\title{
Cavernous hemangioma of the orbit: an unusual acute presentation
}

This article was published in the following Dove Press journal:

International Medical Case Reports Journal

24 July 2017

Number of times this article has been viewed

\author{
Sophia Louisraj' \\ Thendral Ponnudurai' \\ Dominic Rodriguez ${ }^{2}$ \\ Philip A Thomas' \\ Christadoss Arul Nelson \\ Jesudasan' \\ 'Department of Orbit and \\ Oculoplasty, Joseph Eye Hospital, \\ ${ }^{2}$ Department of Medicine, Kauvery \\ Medical Centre, Tiruchirapalli, India
}

\begin{abstract}
We report an unusual presentation of an orbital cavernous hemangioma in a 26-year-old female, who noted sudden redness and swelling of the left eye (LE) on waking up. At presentation, upper eyelid edema with periorbital ecchymosis and subconjunctival hemorrhage were noted in the LE. Although there was transient symptomatic relief with topical medications, blurring of vision developed in the LE. When seen 10 days later, the patient's LE showed axial proptosis. Magnetic resonance imaging revealed an intraconal soft tissue mass in the superomedial quadrant of the left orbit. Superior orbitotomy with mass excision was done; histopathological examination of the excised mass revealed a cavernous hemangioma. The patient had complete visual recovery following surgery. To our knowledge, an acute presentation of an orbital cavernous hemangioma with subconjunctival hemorrhage and periorbital ecchymosis has not previously been reported.
\end{abstract}

Keywords: subconjunctival hemorrhage, ecchymosis, cavernous hemangioma

\section{Introduction}

Cavernous hemangiomas are the most common vascular lesions of the orbit in adults, being commonly seen in middle age, with a female predilection. ${ }^{1}$ Over $80 \%$ of orbital cavernous hemangiomas are located within the intraconal compartment, most commonly in the lateral aspect. ${ }^{2}$ Progressive painless proptosis is the usual mode of presentation, and acute presentations are rare. ${ }^{3}$ We report an unusual acute presentation of an orbital cavernous hemangioma with subconjunctival hemorrhage ( $\mathrm{SCH}$ ) and periorbital ecchymosis.

\section{Case report}

Written informed consent has been provided by the patient to have the case details and any accompanying images published. A 26-year-old female presented with swelling and redness of the left eye (LE) that she noticed on waking up. She had not sustained antecedent trauma or undergone Valsalva maneuver and did not provide any other significant medical history such as bleeding diatheses or drug intake. On examination, the best corrected visual acuity in both eyes was 20/20, N5. The right eye examination was unremarkable. In the $\mathrm{LE}$, there was $\mathrm{SCH}$ involving the bulbar temporal conjunctiva, along with upper eyelid edema and periorbital ecchymosis (Figure 1). The rest of the anterior segment, and the entire posterior segment, were normal. General and systemic examination findings were normal. Hematological investigations did not suggest any bleeding disorder. She was given symptomatic treatment and advised to review after a week. When she returned 10 days later, the swelling and redness were seen to 


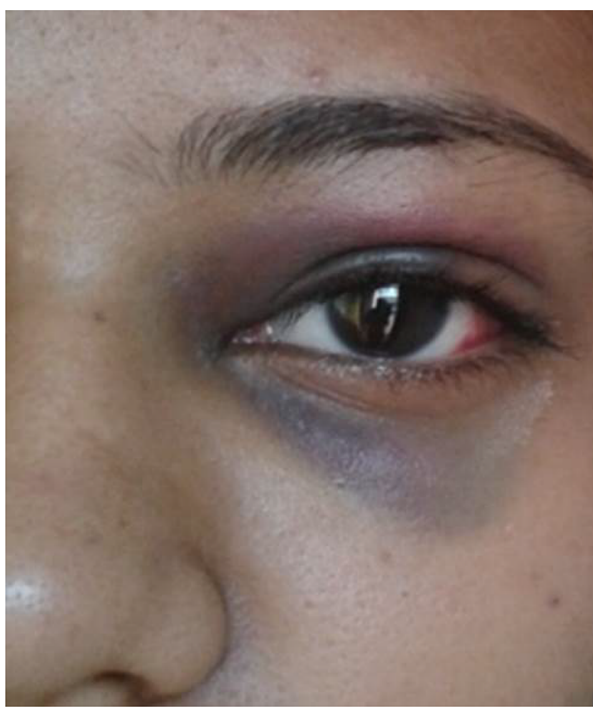

Figure I Initial presentation with subconjunctival hemorrhage and periorbital ecchymosis.

have subsided, but she had developed blurred vision in the LE. The vision in the LE was 20/40, pupils were brisk and reacting normally to light and extraocular movements were full. However, the left eyeball was proptosed with inferior scleral show (Figure 2). Hertels exophthalmometry showed a $3 \mathrm{~mm}$ axial proptosis of the LE, with fundus examination revealing choroidal folds at the posterior pole. Color vision and visual fields were normal. Magnetic resonance imaging revealed a well-defined intraconal mass lesion of size $20 \times 16 \times 15 \mathrm{~mm}$ in the superomedial aspect of left orbit that was T1/T2 hyperintense with a mass effect on optic nerve, medial rectus and posterior surface of globe. The presence of T1 hyperintensity (plain and fat suppression) indicated the presence of blood degradation products suggestive of

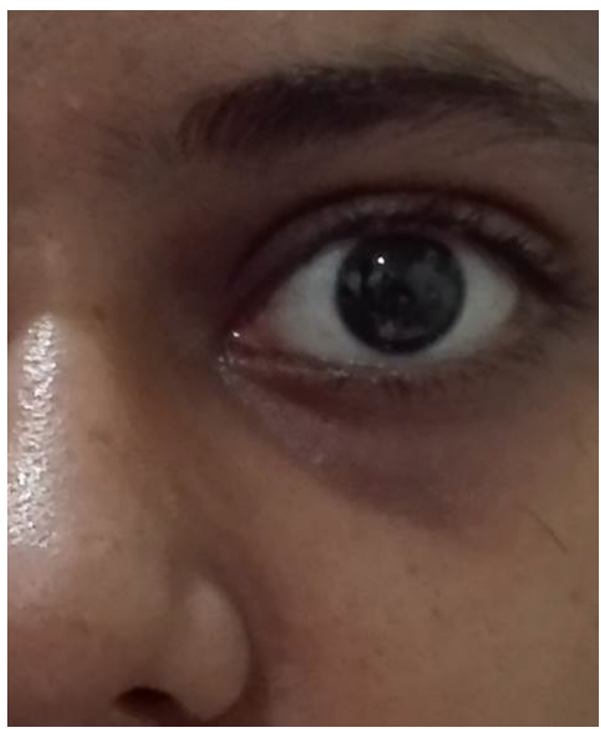

Figure 2 Axial proptosis of the left eye with inferior scleral show.

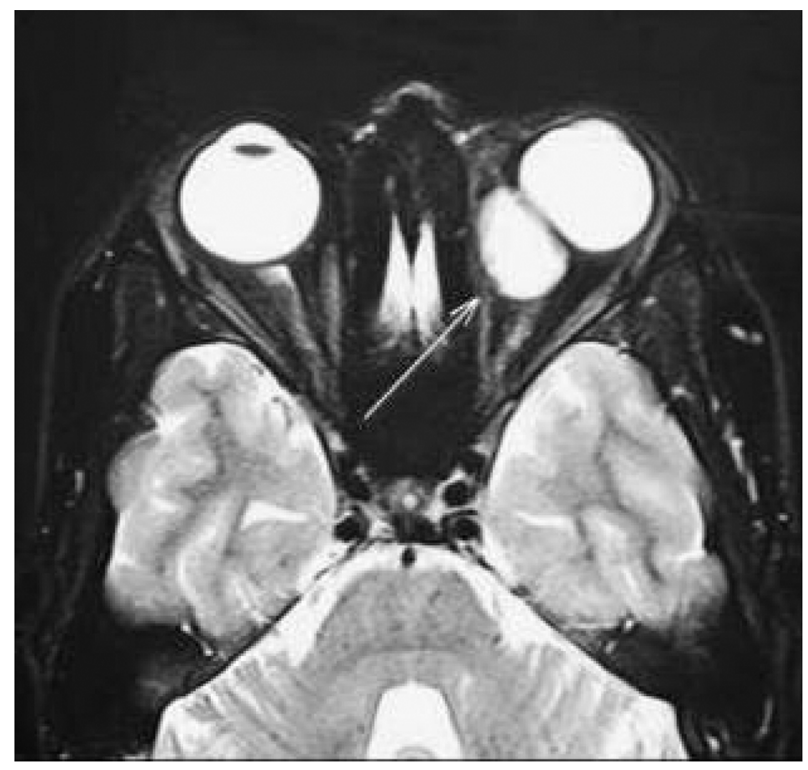

Figure 3 Magnetic resonance imaging (axial section) showing intraconal mass lesion in the left orbit (arrow).

intralesional thrombosis (Figures 3-5). Since the lesion was located behind the globe (retro-ocular), and in order to minimize handling of tissues in the anterior part of the orbit, a transcranial approach was preferred. An intrahairline left frontal scalp incision was made. The frontal bone was cut using craniotome. Working from the orbital side with osteotomes, the roof of the orbit was cut behind the supraorbital margin to raise the orbitofrontal bone flap as a single piece. The posterior portion (medial part) of the roof of the orbit was removed (Figure 6). The periorbita was incised (Figure 7). Dissecting through the fat of the orbit, the medial part of the muscle cone was entered between the medial border of the superior rectus and the medial rectus muscles. The hemangioma was seen as a dark globular mass (Figure 8). It had a good plane of cleavage and initial dissection was done on the lateral surface, then the medial surface and then the anterior surface. The tumor was dissected away from the medial rectus muscle on the medial aspect. The posterior most portion of the tumor was the last to be exposed. There was a single vascular pedicle on the superolateral aspect, which was coagulated and divided to excise the entire mass of the hemangioma (Figure 9). Intraorbital and extradural hemostasis was ensured. The orbitofrontal bone flap was replaced. The patient had no neurological deficits after surgery. The postoperative computerized tomogram confirmed that the mass had been completely excised (Figure 10). Histopathological examination of the excised mass revealed a cavernous hemangioma with an organized hematoma. When seen 1 month after surgery, she was found to have had a complete (20/20) visual recovery (Figure 11). 


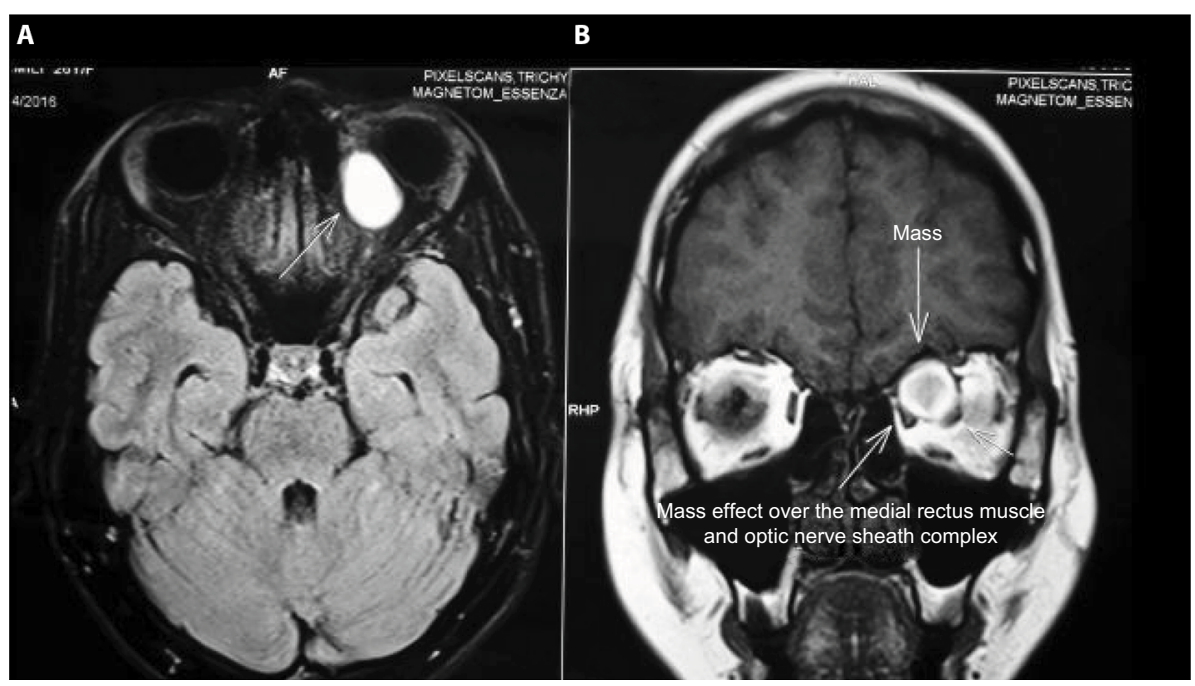

Figure 4 Magnetic resonance imaging of axial (A) and coronal (B) section.

Notes: Magnetic resonance imaging (A) axial section with arrow pointing to the well defined mass lesion seen posterior to the eyeball and (B) coronal section with arrows delineating the lesion to the superomedial quadrant of the orbit.

Abbreviation: RHP, right headend posterior.

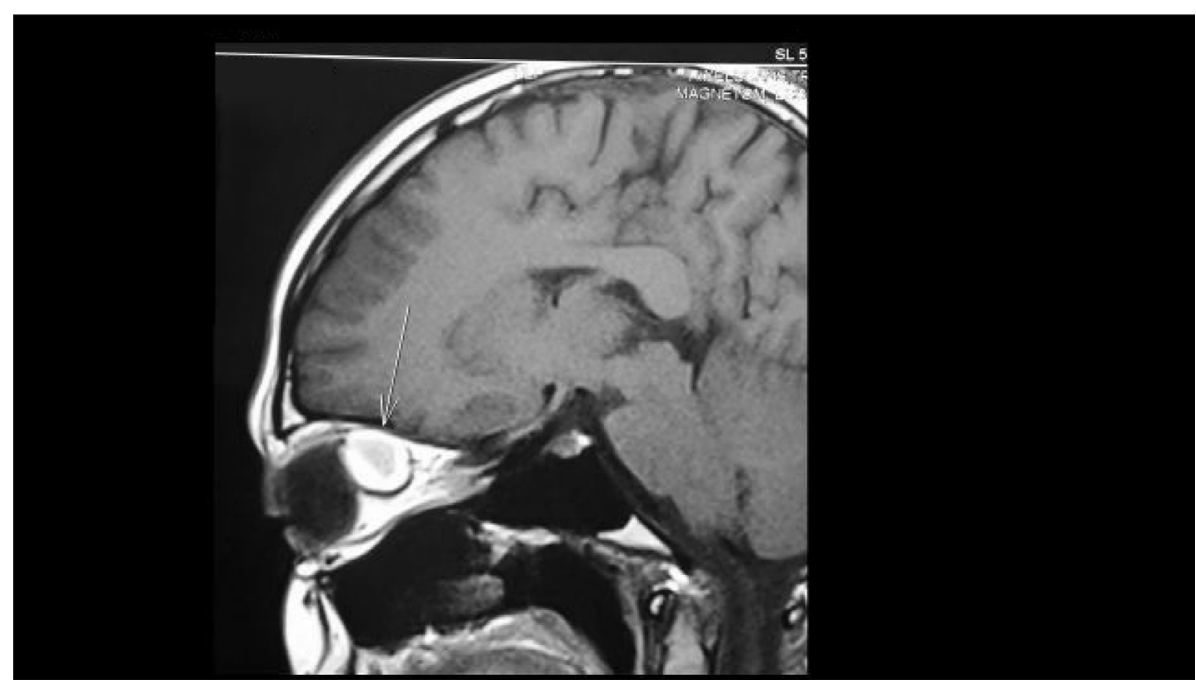

Figure 5 Magnetic resonance imaging showing sagittal section.

Note: Magnetic resonance imaging (sagittal section) showing well defined intraconal mass lesion causing indentation of the posterior part of the eyeball (arrow).

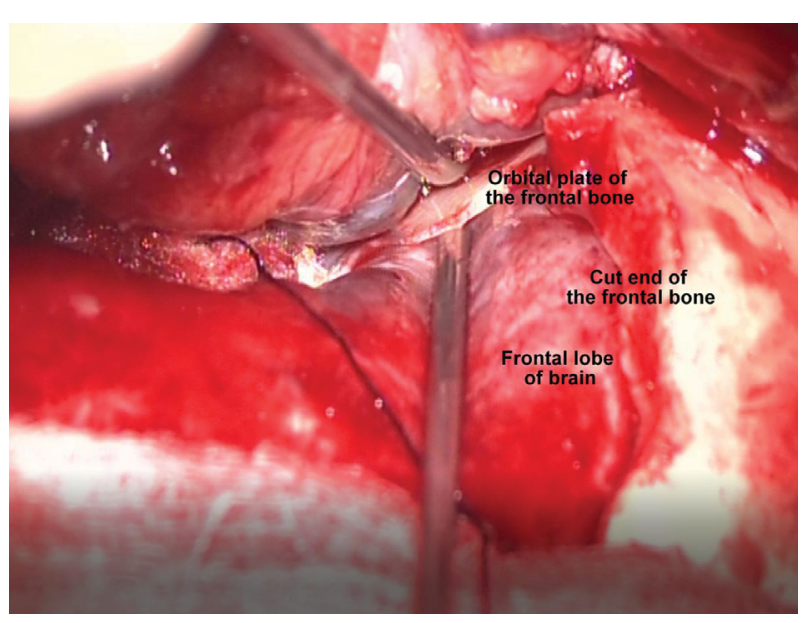

Figure 6 Intraoperative image.

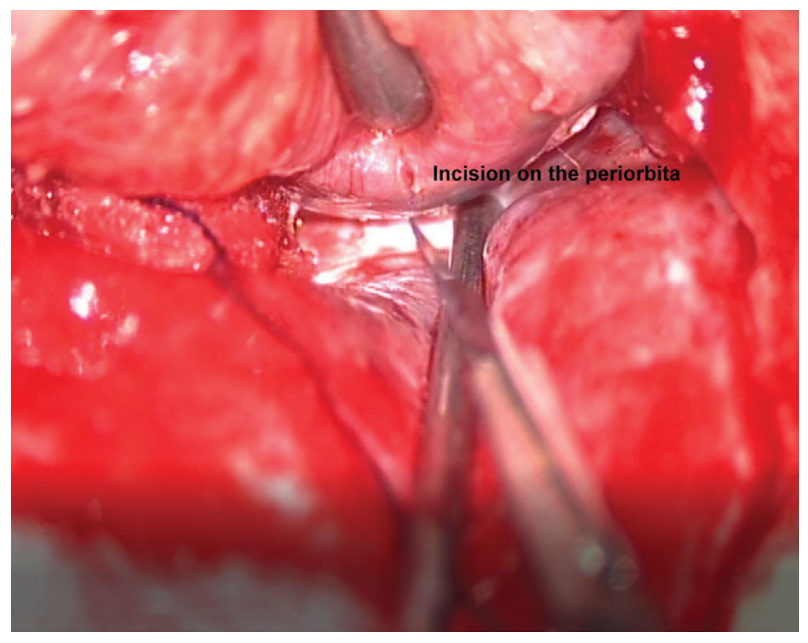

Figure 7 Intraoperative image showing the incision being made on the periorbita. 


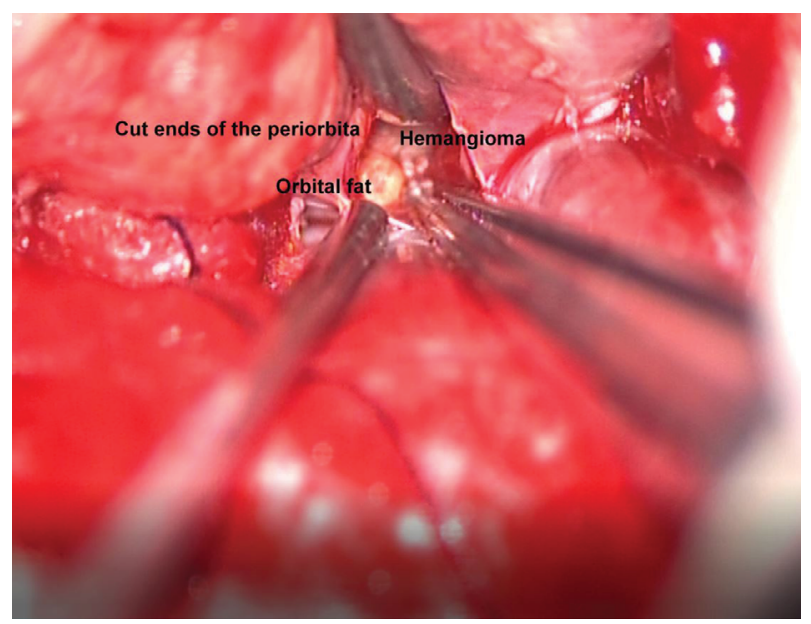

Figure 8 Intraoperative image showing the prolapsing orbital fat and the hemangioma within the cut ends of the periorbita.

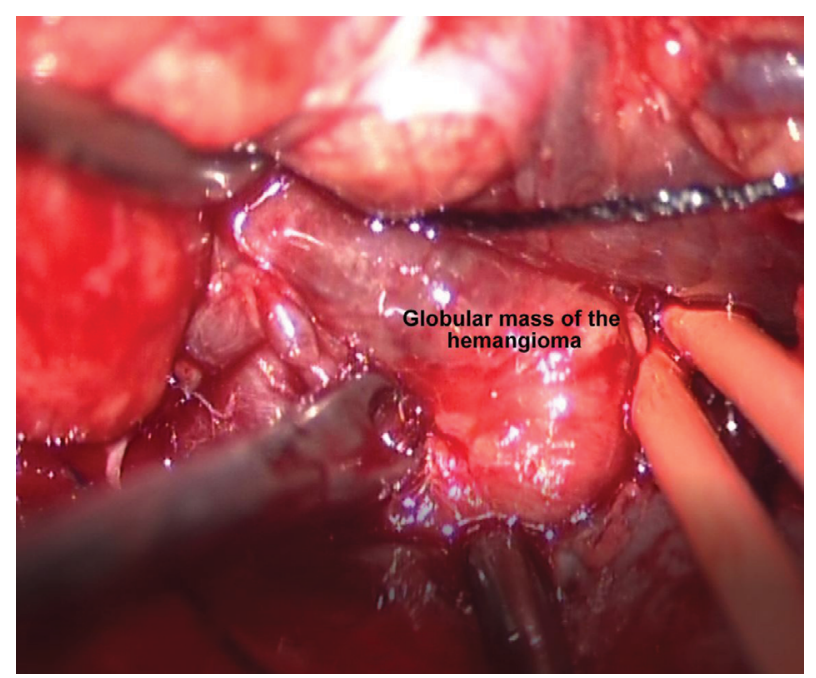

Figure 9 Intraoperative image showing the exposed globular mass of the hemangioma.

\section{Discussion}

Vascular events in the orbit can present acutely. The symptoms or signs can occur due to orbital hemorrhage, acute arteriovenous shunting or subacute thrombosis (typically within orbital veins). Such acute symptoms can either lead to a new diagnosis of underlying vascular disease in some, or there can be an acute deterioration of a vascular disease that was already known, in others. ${ }^{4}$

The most common cause of a spontaneous orbital hemorrhage is an underlying orbital vascular anomaly. ${ }^{5}$ An acute orbital hemorrhage can occur from normal vessels following trauma, Valsalva maneuvers, in hypertensives and in those on antiplatelets or those with bleeding disorders. It can also occur in the presence of congenital or acquired vascular malformations, such as venous-lymphatic malformations (common) and in arteriovenous malformations (rare), as well as from neoplastic vessels (tumors). ${ }^{4}$

Sudden onset of symptoms in an acute vascular event is proposed to be due to hemorrhage from fragile abnormal vessels, acute arteriovenous shunting and subacute thrombosis due to changes in perfusion. The presenting symptoms and signs include proptosis, periocular bruising, episcleral venous congestion, increased intraocular pressure, chemosis and a frank bleeding from the orbit. ${ }^{4}$

A cavernous hemangioma of the orbit, which typically presents as a slow-growing tumor with gradual onset of symptoms, usually causes a mass effect, due to an increase in volume of the orbital contents. The patient may present with a painless, slowly progressive bulging of the globe. A reduction in visual acuity and presence of visual field defects are manifestations of a mass effect or pressure on the optic nerve and surrounding vasculature. Diplopia may occur due to extraocular muscle dysfunction.

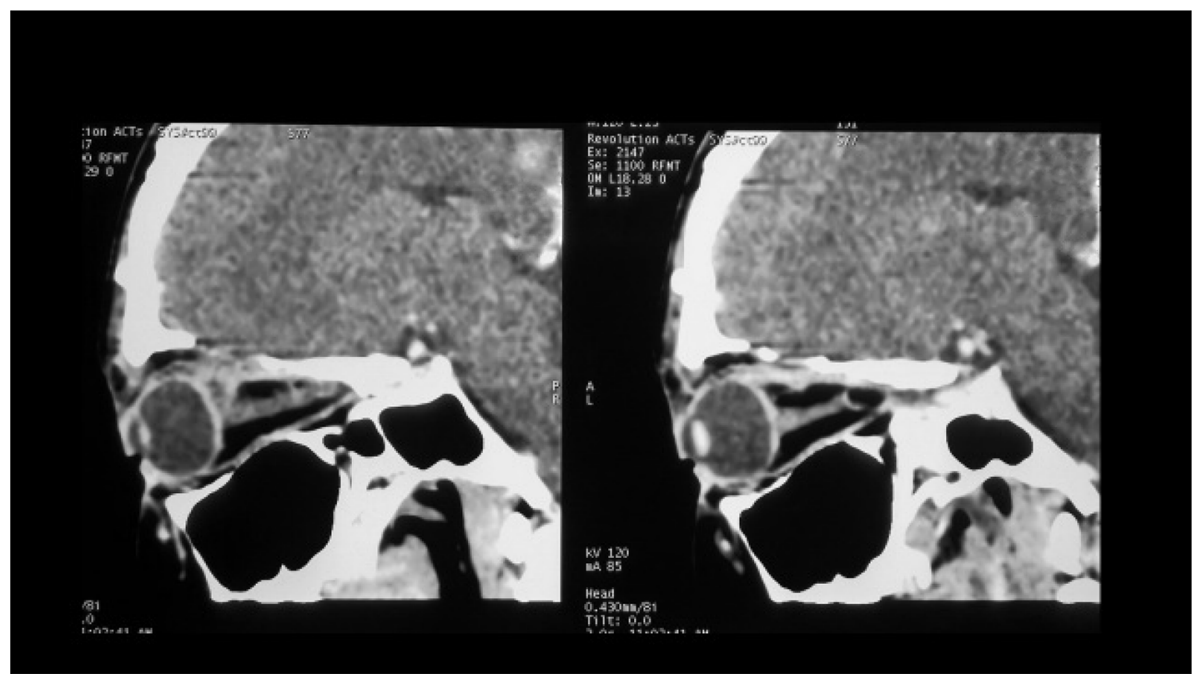

Figure 10 Postoperative CT image.

Abbreviations: $\mathrm{AL}$, anterior left; $\mathrm{PR}$, posterior right. 


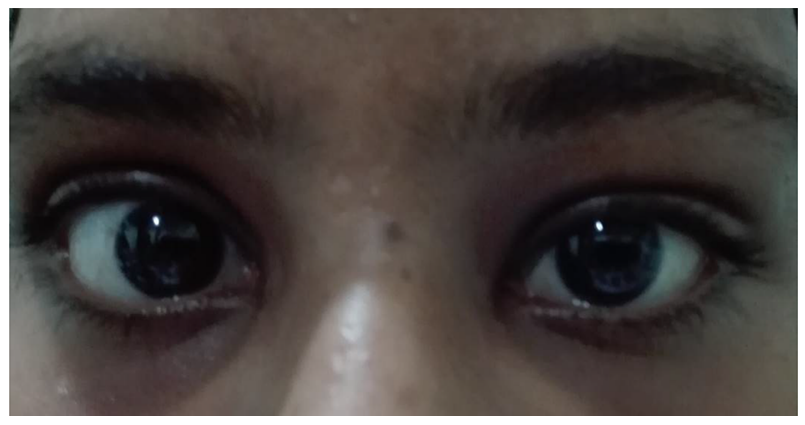

Figure I I Clinical picture I month after surgery.

Lagophthalmos due to extraocular muscle dysfunction or nerve involvement results in exposure keratopathy, keratitis, and corneal perforation. Pupillary dysfunction is sometimes noted due to involvement of neural structures within the orbit. ${ }^{6}$

Spontaneous bleeding in an orbital cavernous hemangioma, with resultant acute onset of symptoms, although extremely rare, has been reported. ${ }^{7}$ Yamamoto et $\mathrm{al}^{7}$ report a spontaneous hemorrhage from orbital cavernous hemangioma resulting in sudden onset of ophthalmopathy in an elderly lady. Arora et $\mathrm{al}^{3}$ describe an acute presentation of an orbital cavernous hemangioma with a visual field defect. Three cases of spontaneous intraorbital hemorrhage caused by cavernous angioma of the orbit have been reported by Zenobii et al. ${ }^{8}$

The mechanism of bleed remains unclear. Some postulates include local hemodynamic changes, hypoxia ${ }^{9}$ and bleeding from capillaries in the sinusoidal space. ${ }^{10} \mathrm{SCH}$ and periorbital ecchymosis noted in our patient may have happened due to the blood tracking within the fascial planes of orbit, following a spontaneous orbital bleed. ${ }^{8}$
A search of the PubMed database, using the keywords "cavernous hemangioma, subconjunctival haemorrhage", "cavernous hemangioma, periorbital ecchymosis" did not generate any relevant published papers. To our knowledge, this is the first case report of an intraconal cavernous hemangioma of the orbit, presenting acutely, with $\mathrm{SCH}$ and periorbital ecchymosis.

\section{Disclosure}

The authors report no conflicts of interest in this work.

\section{References}

1. Ansari SA, Mafee MF. Orbital cavernous hemangioma: role of imaging. Neuroimaging Clin N Am. 2005;15(1):137-158.

2. Anand R, Deria K, Sharma P, Narula M, Garg R. Extraconal cavernous hemangioma of orbit: a case report. Indian J Radiol Imaging. 2008;18(4):310-312.

3. Arora V, Prat MC, Kazim M. Acute presentation of cavernous hemangioma of the orbit. Orbit. 2011;30(4):195-197.

4. Rose GE, Verity DH. Acute presentation of vascular disease within the orbita descriptive synopsis of mechanisms. Eye (Lond). 2013;27(3):299-307.

5. Wills Eye Resident Case Series - Diagnosis and Discussion. Available from: https://www.reviewofophthalmology.com/.../wills-eye-residentcase-series-diagnosis-accessed. Accessed January 10, 2017.

6. Cohen AJ, Mercandetti M, Weinberg DA [webpage on the Internet] Hemangioma, Cavernous (Aug 2008). Available from: http://emedicine medscape.com/article/12,18,120- overview. Accessed May 25, 2016.

7. Yamamoto J, Takahashi M, Nakano Y, et al. Spontaneous hemorrhage from orbital cavernous hemangioma resulting in sudden onset of ophthalmopathy in an adult - case report. Neurol Med Chir (Tokyo). 2012;52(10):741-744.

8. Zenobii M, Galzio RJ, Lucantoni D, Caffagni E, Magliani V. Spontaneous intraorbital hemorrhage caused by cavernous angioma of the orbit J Neurosurg Sci. 1984;28(1):37-40.

9. McNab AA, Wright JE. Cavernous haemangiomas of the orbit. Aust $N$ Z J Ophthalmol. 1989;17(4):337-345.

10. Harris GJ, Jakobiec FA. Cavernous hemangioma of the orbit. J Neurosurg. 1979;51(2):219-228.
The International Medical Case Reports Journal is an international, peer-reviewed open-access journal publishing original case reports from all medical specialties. Previously unpublished medical posters are also accepted relating to any area of clinical or preclinical science. Submissions should not normally exceed 2,000 words or

\section{Dovepress}

4 published pages including figures, diagrams and references. The manuscript management system is completely online and includes a very quick and fair peer-review system, which is all easy to use. Visit http://www.dovepress.com/testimonials.php to read real quotes from published authors. 